\title{
Differences between men with screening-detected versus clinically diagnosed prostate cancers in the USA Richard M Hoffman ${ }^{1,2}$, S Noell Stone*2,3, David Espey ${ }^{4}$ and Arnold L Potosky 5
}

\author{
Address: ${ }^{1}$ Medicine Service, New Mexico VA Health Care System, Albuquerque, New Mexico, USA, ${ }^{2}$ New Mexico Tumor Registry, University of New \\ Mexico Health Sciences Center, Albuquerque, New Mexico, USA, ${ }^{3}$ Non-communicable Disease Epidemiology Unit, London School of Hygiene \\ and Tropical Medicine, London, UK, ${ }^{4} \mathrm{CDC}$ Division of Cancer Prevention and Control and Indian Health Service National Epidemiology \\ Program, Albuquerque, New Mexico, USA and ${ }^{5}$ Division of Cancer Control and Population Sciences, National Cancer Institute, Bethesda, \\ Maryland, USA \\ Email: Richard M Hoffman - rhoffman@unm.edu; S Noell Stone* - noells@nmtr.unm.edu; David Espey - david.espey@ihs.gov; \\ Arnold L Potosky - potoskya@mail.nih.gov \\ * Corresponding author
}

Published: 08 March 2005

BMC Cancer 2005, 5:27 doi:10.1/86/147|-2407-5-27
Received: 04 October 2004

Accepted: 08 March 2005

This article is available from: http://www.biomedcentral.com/I47/-2407/5/27

(C) 2005 Hoffman et al; licensee BioMed Central Ltd.

This is an Open Access article distributed under the terms of the Creative Commons Attribution License (http://creativecommons.org/licenses/by/2.0), which permits unrestricted use, distribution, and reproduction in any medium, provided the original work is properly cited.

\begin{abstract}
Background: The advent of prostate specific antigen (PSA) testing in the United States of America (USA) has led to a dramatic increase in the incidence of prostate cancer in the United States as well as the number of men undergoing aggressive treatment with radical prostatectomy and radiation therapy. We compared patient characteristics and treatment selection between American men with screening-detected versus clinically diagnosed prostate cancers.
\end{abstract}

Methods: We evaluated 3,173 men with prostate cancer in the USA. Surveys and medical records provided information on demographics, socioeconomic status, comorbidities, symptoms, tumor characteristics, and treatment. We classified men presenting with symptoms of advanced cancer bone pain, weight loss, or hematuria - as "clinically diagnosed"; asymptomatic men and those with only lower urinary tract symptoms were considered "screening-detected." We used multivariate analyses to determine whether screening predicted receiving aggressive treatment for a clinically localized cancer.

Results: We classified II\% of cancers as being clinically diagnosed. Men with screening-detected cancers were more often non-Hispanic white $(77 \%$ vs. $65 \%, \mathrm{P}<0.0 \mathrm{l})$, younger $(36 \%<65$ years vs. $25 \%, \mathrm{P} \leq 0.0 \mathrm{I})$, better educated $(80 \% \geq$ high school vs. $67 \%, \mathrm{P}<0.0 \mathrm{I})$, healthier ( $18 \%$ excellent health vs. $10 \%, P<0.01)$, and diagnosed with localized disease $(90 \%$ vs. $75 \%, P<0.01)$. Men with screening-detected localized cancers more often underwent aggressive treatment, $76 \%$ vs. $70 \%, P$ $=0.05$.

Conclusion: Most cancers were detected by screening in this American cohort. Appropriately, younger, healthier men were more likely to be diagnosed by screening. Minority status and lower socio-economic status appeared to be screening barriers. Screening detected earlier-stage cancers and was associated with receiving aggressive treatment. 


\section{Background}

Prostate-specific antigen (PSA) testing was introduced in the United States of America (USA) in the late 1980s with Federal Drug Administration (FDA) approval for prostate cancer surveillance [1]. However, the test indications were soon expanded to include prostate cancer screening. By the early 1990s, the American Urologic Association and the American Cancer Society were recommending PSA testing, along with digital rectal examination (DRE), as part of annual prostate cancer screening [2,3]. The advent of PSA testing led to a dramatic increase in the incidence of prostate cancer in the USA, with the number of new cases rising from 152,811 in 1990 to over 230,000 in 1992 [4,5]. During the past decade, the number of American men undergoing aggressive treatment with radical prostatectomy and radiation therapy also increased substantially $[6,7]$.

Urologic screening studies provide the most comprehensive information about the men undergoing PSA screening [8-10]. Several trials have taken place in both Europe and the USA. In general, study subjects usually were recruited through advertisements and they were screened with combinations of PSA, DRE, and transrectal ultrasound. The average age of these study participants was in the mid-60s, and minority subjects were not well represented. Minimal data were provided on symptoms, comorbidity, or socioeconomic status. Among American men diagnosed with clinically localized prostate cancers, approximately $90 \%$ underwent treatment with radical prostatectomy or radiation therapy.

Population-based data on PSA screening are largely unavailable, including information on the proportion of prostate cancers diagnosed by screening, the demographic, socioeconomic, and clinical characteristics of men with screening-detected cancers, and the association of screening detection with treatment decisions. We used data from the United States-based Prostate Cancer Outcomes Study (PCOS) to 1) determine the proportion of screening-detected prostate cancers in a population-based cohort, 2) compare baseline demographic, socioeconomic, and clinical characteristics between men with screening-detected versus clinically diagnosed cancers, and 3) determine whether men with screening-detected clinically-localized prostate cancers were more likely to undergo aggressive treatment (radical prostatectomy or radiation therapy).

\section{Methods \\ Study population}

The American National Cancer Institute instituted the PCOS in 1994 to measure practice patterns and healthrelated quality of life among men diagnosed with prostate cancer in the United States. Methods for this multi-site, longitudinal project are described elsewhere [11]. Briefly, PCOS subjects were men histologically diagnosed with prostate cancer between October 1, 1994 and October 31, 1995. Subjects were identified using a rapid case ascertainment system by the six participating National Cancer Institute Surveillance, Epidemiology and End Results (SEER) cancer registries (Atlanta, Georgia metropolitan area; Los Angeles County California; King County, Washington; Connecticut; Utah; and New Mexico). Eligible subjects were residents of the areas covered by these registries at the time of diagnosis and were between the ages of 39 and 89 years, except in King County, where only men over 60 years were eligible. The institutional review board of each participating institution approved the study.

Eligible patients were sampled within strata of age, race/ ethnicity, and tumor registry to approximate a sample representative of the United States population of prostate cancer patients. The PCOS oversampled younger men and minorities and excluded patients with race/ethnicity other than non-Hispanic white, African American, or Hispanic, because their sample sizes were small.

A total of 11,137 men with prostate cancer comprised the eligible patient population for the study and the PCOS randomly selected 5,672 of these men. Among these selected patients, 3173 (55.9\%) completed a healthrelated quality-of-life survey questionnaire 6 months after initial diagnosis. We used survey and medical record data collected from these subjects to evaluate differences in patient characteristics and treatments between men with screening-detected cancers and those who were diagnosed clinically. Responders to the PCOS survey were younger than non-responders and more likely to be non-Hispanic white and have a higher socioeconomic status. A substantial proportion of the responders had regional stage and moderately differentiated cancers, while non-responders had a greater proportion of distant stage and poorly differentiated cancers. Responders also were more likely to receive radical prostatectomy [11].

\section{Data collection}

Investigators contacted eligible subjects by mail and/or telephone requesting them to sign a release form allowing review of all medical records from any physicians and facilities diagnosing and/or providing care for prostate cancer. Records were obtained from private and public hospitals, freestanding radiological or surgical centers, Veterans Administration hospitals, Health Maintenance Organizations, and private physician offices. Certified Tumor Registry abstractors collected baseline information on demographics, clinical symptoms before diagnosis (systemic and urinary), comorbidity, diagnostic procedures and results (including PSA levels and digital rectal examination findings), clinical staging, tumor 
characteristics, and treatment details. The PCOS reabstracted a random sample of $5 \%$ of records to assess and correct any systematic coding errors.

The PCOS also collected data on general and disease-specific measures of health-related quality of life, symptoms, comorbidity, and specific treatments received for prostate cancer using a mailed self-administered questionnaire. Most respondents completed the self-administered questionnaire $(91 \%)$; those who did not return the questionnaire were contacted by telephone and asked to complete the survey by telephone or in person. Subjects were asked to recall their health-related quality of life and symptoms, including the domains of urinary, bowel, and sexual function, just before their prostate cancer was diagnosed. Demographic and socioeconomic questions from this survey were used to determine race/ethnicity, employment status, educational level, household income, insurance status, and marital status. A question assessing comorbidity asked about 12 medical conditions that were likely to affect prostate cancer treatment decisions and long-term quality of life. The conditions were derived from the Charlson index as well as the expert opinion of the PCOS investigators [12]. If the patient reported being told by a doctor that he had cerebrovascular disease, inflammatory bowel disease, liver disease, or ulcers, he received one point on his comorbidity score for each condition. If the patient reported that any of eight conditions - arthritis, diabetes, depression, hypertension, chest pain, heart attack, heart failure, or chronic lung disease - limited his activity or required prescription medications, he received 1 additional point for each of these conditions. In the analyses, comorbidity scores were divided into the categories of $0,1,2$, and greater than or equal to 3 points.

We assigned screening status using information from the medical record abstract and the patient questionnaire. We considered men presenting with symptoms consistent with advanced prostate cancer, including bone pain, weight loss or hematuria, to be "clinically diagnosed." We initially created separate categories for men with only irritative or obstructive symptoms consistent with benign prostatic hyperplasia and an asymptomatic group who had neither prostate cancer nor lower urinary tract symptoms.

Clinical cancer stage was based on an algorithm using information abstracted from medical records. The algorithm was necessary because the community-based medical records were not detailed enough to classify cases by TNM (tumor, node, metastases) staging [13]. The algorithm defined $\mathrm{T} 1$ tumors as confined to the prostate with a normal digital rectal examination and no positive scans (magnetic resonance imaging, computed tomography, bone scan) or evidence of metastases. T2 tumors were defined as confined to the prostate, with abnormal or suspicious digital rectal examinations, but no positive scans or evidence of metastases. We defined clinically localized cancers as either T1 or T2 tumors. Initial treatment, based on medical record abstractions, was defined as treatment received within the first six months after diagnosis. We defined aggressive treatment as either radical prostatectomy or radiation therapy. We defined conservative management as androgen deprivation, either surgical or chemical, or watchful waiting.

\section{Statistical analyses}

Descriptive statistics were calculated for ethnicity/race, age, stage at diagnosis, education, marital status, employment, income, digital rectal exam and PSA results, Gleason score from biopsy or transurethral resection of the prostate, comorbid conditions and self-reported general health status. We used contingency tables to compare men presenting without any symptoms, those with lower urinary tract symptoms alone, and those with prostate cancer symptoms. Although screening is defined as applying a diagnostic test to asymptomatic people [14], the prevalence of benign prostatic hyperplasia is very high among men at risk for prostate cancer [15]. We found that the men with only lower urinary tract symptoms were much more similar to asymptomatic men than to men we classified as having clinically diagnosed cancers. Therefore, we also considered cancers diagnosed in men who reported only lower urinary tract symptoms at the time of PSA testing to be "screening-detected." We used this combined screening-detected group to compare baseline characteristics against clinically diagnosed cases and in modeling treatment selection for clinically localized cancers. Logistic regression analyses were used to determine whether screening history was independently associated with selecting aggressive treatment versus conservative management among men with clinically localized prostate cancer. Covariates for this multivariate model, based on previous literature, included age, race/ethnicity, marital status, study site, education, insurance status, annual income, comorbidity, health status, and tumor characteristics $[16,17]$. We also examined interactions between screening status with age, comorbidity, PSA level, and Gleason score.

The results of the logistic regression models are shown as percentages receiving the treatment of interest, adjusting for the independent variables included in the model. These percentages were directly adjusted to the distribution of the variables among the weighted sample used in each model [18]. The probability of receiving the treatment of interest can then be directly compared across levels of the variables included in the model. 
Table I: Baseline demographic and socioeconomic characteristics.

\begin{tabular}{|c|c|c|}
\hline Variable & $\begin{array}{c}\text { Number of } \\
\text { subjects (Sample } \\
\text { size }=3173)\end{array}$ & $\begin{array}{l}\text { Weighted } \\
\text { percentages }\end{array}$ \\
\hline \multicolumn{3}{|l|}{ SEER registry } \\
\hline Atlanta & 316 & 22.5 \\
\hline Connecticut & 669 & 35.8 \\
\hline Los Angeles & 938 & 13.5 \\
\hline New Mexico & 342 & 11.5 \\
\hline Seattle & 325 & 6.0 \\
\hline Utah & 583 & 10.8 \\
\hline \multicolumn{3}{|l|}{ Ethnicity } \\
\hline Non-Hispanic white & 2187 & 75.7 \\
\hline Non-Hispanic black & 539 & 13.8 \\
\hline Hispanic & 447 & 10.5 \\
\hline \multicolumn{3}{|l|}{ Age } \\
\hline$<49$ & 102 & 2.3 \\
\hline $50-64$ & 1137 & 32.3 \\
\hline $65-74$ & 1336 & 44.5 \\
\hline $75+$ & 598 & 20.9 \\
\hline \multicolumn{3}{|l|}{ Current marital status } \\
\hline Married & 2499 & 78.6 \\
\hline Unmarried & 637 & 20.3 \\
\hline Unknown & 37 & I.I \\
\hline \multicolumn{3}{|l|}{ Education } \\
\hline$<$ High school degree & 695 & 20.9 \\
\hline High school/some college & 1419 & 43.6 \\
\hline$\geq$ College degree & 1014 & 34.0 \\
\hline Unknown & 45 & 1.5 \\
\hline \multicolumn{3}{|l|}{ Insurance } \\
\hline Private & 2595 & 82.1 \\
\hline Public/Medicare & 309 & 10.0 \\
\hline Unknown & 269 & 7.9 \\
\hline \multicolumn{3}{|l|}{ Income (annual) } \\
\hline$<\$ 20,000$ & 792 & 23.3 \\
\hline$\$ 20-40,000$ & 921 & 28.8 \\
\hline$\$ 40,000+$ & 1128 & 36.3 \\
\hline Unknown & 332 & 11.6 \\
\hline
\end{tabular}

Legend: SEER = Surveillance, Epidemiology, and End Results

All analyses were performed with the Survey Data Analysis statistical package (Research Trial Institute, Research Triangle Park, North Carolina, 1997) to account for the complex survey design. We obtained unbiased estimates of parameters for all eligible prostate cancer patients in the PCOS areas by using the Horvitz-Thompson weight, which is the inverse of the sampling proportion for each sampling stratum (defined by age, race/ethnicity, and study area). A two-tailed P-value of $<.05$ was considered statistically significant.

\section{Results}

The baseline demographic, socioeconomic, and clinical characteristics of the PCOS subjects are shown in Tables 1 and 2 . The majority of subjects were non-Hispanic white
Table 2: Baseline clinical characteristics.

\begin{tabular}{|c|c|c|}
\hline Variable & $\begin{array}{c}\text { Number of } \\
\text { subjects (sample } \\
\text { size }=3173 \text { ) }\end{array}$ & $\begin{array}{l}\text { Weighted } \\
\text { percentages }\end{array}$ \\
\hline \multicolumn{3}{|l|}{ Symptoms } \\
\hline Asymptomatic & 1001 & 30.9 \\
\hline Lower urinary alone & 1832 & 58.4 \\
\hline Systemic & 340 & 10.7 \\
\hline \multicolumn{3}{|l|}{ Comorbid conditions } \\
\hline None & $121 \mid$ & 37.2 \\
\hline I & 1008 & 32.5 \\
\hline 2 & 520 & 16.3 \\
\hline $3+$ & 434 & 13.9 \\
\hline \multicolumn{3}{|l|}{ Health status } \\
\hline Excellent & 534 & 16.9 \\
\hline Good & 2104 & 66.2 \\
\hline Fair or poor & 500 & 15.9 \\
\hline Unknown & 35 & 1.0 \\
\hline \multicolumn{3}{|l|}{ PSA (ng/ml) } \\
\hline$<4$ & 294 & 8.8 \\
\hline$\geq 4$ & 2675 & 84.5 \\
\hline Unknown & 204 & 6.7 \\
\hline \multicolumn{3}{|l|}{ Digital rectal examination } \\
\hline Abnormal & $|74|$ & 54.8 \\
\hline Normal & 1033 & 33.2 \\
\hline Unknown & 399 & 12.0 \\
\hline \multicolumn{3}{|l|}{ Gleason score } \\
\hline $2-4$ & 481 & 13.9 \\
\hline $5-7$ & 2029 & 65.1 \\
\hline $8-10$ & 373 & 11.6 \\
\hline Unknown & 290 & 9.4 \\
\hline \multicolumn{3}{|l|}{ Tumor stage } \\
\hline Local & 2796 & 88.7 \\
\hline Regional & 126 & 3.7 \\
\hline Advanced & 251 & 7.6 \\
\hline
\end{tabular}

Legend: PSA = prostate-specific antigen

men, older than sixty-five, and married at the time of diagnosis. Socioeconomic status was relatively high; a majority had more than a high school education, and a substantial proportion of subjects had private insurance. Among the study subjects, $10.7 \%$ presented with symptoms consistent with prostate cancer and were considered to be clinically diagnosed cases. Nearly two-thirds of subjects had lower urinary tract symptoms, while $30.9 \%$ were completely asymptomatic. Overall, $83.1 \%$ of men rated their general health at "good" or "excellent" before their cancer diagnosis.

We compared baseline characteristics of asymptomatic men, those with lower urinary tract symptoms alone, and men with clinically diagnosed cancers in Table 3 . We found that the characteristics of men with lower urinary tract symptoms alone were closer to the asymptomatic men than to the clinically diagnosed cancer cases for race/ ethnicity, socioeconomic status, health status, and cancer 
Table 3: Distribution of baseline demographic, socioeconomic, and clinical characteristics by screening status.

\begin{tabular}{|c|c|c|c|c|}
\hline Variable & $\begin{array}{l}\text { Clinically diagnosed } \\
\text { (weighted \%) }\end{array}$ & $\begin{array}{c}\text { Asymptomatic* (weighted } \\
\% \text { ) }\end{array}$ & LUTS*** (weighted \%) & $\begin{array}{l}\text { Asymptomatic or LUTS**** } \\
\text { (weighted \%) }\end{array}$ \\
\hline SEER registry & & $P=0.16^{*}$ & $P=0.31 * *$ & $P=0.24 * * *$ \\
\hline Atlanta & 14.2 & 14.2 & 12.9 & 13.3 \\
\hline Connecticut & 19.1 & 24.7 & 21.9 & 22.9 \\
\hline Los Angeles & 38.1 & 34.5 & 36.0 & 35.5 \\
\hline New Mexico & 13.7 & 9.8 & 12.0 & 11.3 \\
\hline Seattle & 4.3 & 5.9 & 6.4 & 6.2 \\
\hline Utah & 10.5 & 10.9 & 10.8 & 6.8 \\
\hline Ethnicity & & $P<0.01$ & $P<0.01$ & $P<0.01$ \\
\hline Non-Hispanic white & 65.1 & 79.9 & 75.5 & 77.0 \\
\hline Non-Hispanic black & 20.8 & 12.4 & 13.3 & 13.0 \\
\hline Hispanic & 14.1 & 7.8 & 11.2 & 10.0 \\
\hline Age & & $P<0.01$ & $P=0.38$ & $P \leq 0.01$ \\
\hline$<49$ & 2.2 & 4.1 & $\mathrm{I} .4$ & 2.3 \\
\hline $50-64$ & 22.8 & 40.5 & 29.7 & 33.4 \\
\hline $65-74$ & 50.7 & 38.7 & 46.5 & 43.8 \\
\hline $75+$ & 24.4 & 16.7 & 22.4 & 20.5 \\
\hline Current marital status & & $P<0.01$ & $P=0.03$ & $P=0.01$ \\
\hline Married & 72.9 & 81.4 & 79.7 & 80.3 \\
\hline Unmarried & 27.1 & 18.6 & 20.3 & 19.7 \\
\hline Education & & $P<0.01$ & $P<0.01$ & $P<0.01$ \\
\hline$<$ High school degree & 33.3 & 16.2 & 21.7 & 19.8 \\
\hline High school/college & 37.6 & 45.5 & 44.8 & 45.0 \\
\hline$\geq$ College degree & 29.7 & 38.3 & 33.5 & 35.2 \\
\hline Income (annual) & & $P<0.01$ & $P=0.01$ & $P<0.01$ \\
\hline$<\$ 20,000$ & 36.8 & 19.0 & 28.4 & 25.1 \\
\hline$\$ 20-40,000$ & 35.9 & 30.3 & 33.2 & 32.2 \\
\hline$\$ 40,000+$ & 27.3 & 50.7 & 38.4 & 42.7 \\
\hline Insurance & & $P<0.01$ & $P=0.23$ & $P=0.01$ \\
\hline Private & 39.7 & 48.9 & 44.0 & 44.3 \\
\hline Public/Medicare & 53.1 & 42.7 & 48.2 & 48.2 \\
\hline Unknown & 6.4 & 8.4 & 7.9 & 8.1 \\
\hline Comorbid conditions & & $P \leq 0.01$ & $P=0.4 I$ & $P=0.05$ \\
\hline None & 32.2 & 41.8 & 35.8 & 37.8 \\
\hline 1 & 30.3 & 34.0 & 32.2 & 32.8 \\
\hline 2 & 17.6 & 16.4 & 16.1 & 16.2 \\
\hline $3+$ & 19.8 & 7.8 & 16.0 & 13.2 \\
\hline Health status & & $P<0.01$ & $P<0.01$ & $P<0.01$ \\
\hline Excellent & 9.9 & 23.0 & 15.2 & 17.9 \\
\hline Good & 63.5 & 68.9 & 66.5 & 67.3 \\
\hline Fair or poor & 26.6 & 8.1 & 18.3 & 14.8 \\
\hline PSA (ng/ml) & & $P=0.01$ & $P=0.20$ & $P=0.05$ \\
\hline$<4$ & 11.7 & 7.0 & 9.3 & 8.5 \\
\hline$\geq 4$ & 78.5 & 87.9 & 83.7 & 85.2 \\
\hline Unknown & 9.8 & 5.1 & 7.0 & 6.4 \\
\hline Digital rectal examination & & $P=0.10$ & $P=0.07$ & $P=0.06$ \\
\hline Abnormal & 59.4 & 54.0 & 54.3 & 54.2 \\
\hline Normal & 27.0 & 34.0 & 33.9 & 33.9 \\
\hline Unknown & 13.6 & 12.0 & 11.7 & 11.9 \\
\hline Gleason score & & $P<0.01$ & $P<0.01$ & $P<0.01$ \\
\hline
\end{tabular}


Table 3: Distribution of baseline demographic, socioeconomic, and clinical characteristics by screening status. (Continued)

\begin{tabular}{lcccc}
\hline $2-4$ & 9.6 & 13.6 & 14.9 & 14.4 \\
$5-7$ & 53.4 & 69.9 & 64.6 & 66.5 \\
$8-10$ & 22.3 & 8.3 & 11.4 & 10.3 \\
Unknown & 14.7 & 8.2 & 9.1 & 8.8 \\
Tumor stage & & $\mathrm{P}<0.01$ & $8<0.01$ & $\mathrm{P}$ \\
$\quad$ Local & 74.6 & 92.8 & 89.1 & 90.01 \\
Regional & 4.0 & 3.2 & 4.0 & 3.7 \\
Advanced & 21.4 & 4.0 & 7.0 & 5.9 \\
\hline
\end{tabular}

*P value comparing asymptomatic cases with clinically diagnosed cases.

** $\mathrm{P}$ value comparing lower urinary tract symptoms alone cases with clinically diagnosed cases.

***P value comparing asymptomatic and lower urinary tract symptoms alone cases with clinically diagnosed cases.

Legend: LUTS = lower urinary tract symptoms, SEER = Surveillance, Epidemiology, and End Results; PSA = prostate-specific antigen

grade and stage. When we combined these two groups into a single category of screening-detected cases, we found significant differences between the screeningdetected and clinically diagnosed cases. Men with screening-detected cancers were more likely to be non-Hispanic white, were younger age, and had a higher socioeconomic status. They also reported being healthier and were more likely to have early stage disease.

We then evaluated whether screening status independently predicted receiving aggressive treatment among the 2796 men who were diagnosed with clinically localized cancer. The primary treatment for these men was radical prostatectomy for 1535 (53.4\%), while 518 (20.6\%) underwent radiation therapy, 671 (26.0\%) were treated conservatively; we had no treatment information for 72 subjects $(2.5 \%)$. The results of the multivariate analysis are shown in Table 4. After adjusting for age, race/ethnicity, marital status, area of the country, education, insurance coverage, annual income, comorbidity, self-reported health status, and tumor characteristics, we found that men with screening-detected cancers were more likely to receive aggressive treatment. The adjusted percentage of men with screening-detected cancers undergoing aggressive treatment was $76 \%(95 \%$ CI $0.74,0.78)$ vs. $70 \%$ (95\% CI 0.64, 0.76), in men with clinically diagnosed cancers, $\mathrm{OR}=1.5(95 \%$ CI 1.1, 2.3), $\mathrm{P}=0.05$. Other factors that were significantly associated with aggressive treatment included geographic area, ethnicity, age, marital status, comorbidity, health status, and tumor characteristics. We found no significant interactions for treatment selection between screening status with age, comorbidity, PSA level, or Gleason score.

\section{Discussion}

We found that the majority of cancers $(89.3 \%)$ in a population-based PCOS cohort were detected by screening. Compared to men with clinically diagnosed prostate cancer, men with screening-detected cancers were younger, more likely to be married, less likely to be a member of a minority group, and in better health. The cancers detected by screening were more likely to be clinically localized and less likely to be poorly differentiated. Among men with clinically localized prostate cancers, those with screening-detected cancers were significantly more likely to undergo aggressive treatment, even after adjusting for demographics, comorbidity, and tumor characteristics

Our finding that a high proportion of prostate cancers diagnosed in 1994 and 1995 were detected by screening is consistent with the temporal correlation between the increased use of PSA testing and the increased incidence of prostate cancer in the USA beginning during the early 1990s [4,5]. Although prostate cancer incidence rates decreased for several years in the mid 1990s, more recent data show that incidence rates are again increasing $[5,19,20]$ and survey results from the Centers for Disease Control's Behavioural Risk Factor Surveillance System (BRFSS) show that a high proportion of American men continue to undergo PSA testing [20]. These data suggest that our findings are still relevant for prostate cancers being diagnosed in the USA. We also found that men with screening detected cancers were more likely to have early stage cancers, again mirroring the epidemiologic data showing an increased incidence of early stage cancers and a decreased incidence of advanced stage cancers $[4,5]$. The majority of screening-detected tumors were moderately to poorly differentiated; however, a significantly higher proportion of clinically diagnosed cancers were poorly differentiated.

Previous data, including an analysis of the PCOS cohort, have shown African Americans to be twice as likely as non-Hispanic whites to present with advanced stage cancers $[4,5,21]$. In the current analysis, we found a greater prevalence of ethnic/racial minorities in the clinically diagnosed versus screening-detected cancers. This disparity may reflect ethnic/racial differences in accessing preventive health care services, particularly arising from socioeconomic barriers. This in turn could contribute to 
Table 4: Multivariate model of factors associated with undergoing aggressive ${ }^{a}$ treatment for clinically localized cancer $(n=2796)$.

\begin{tabular}{|c|c|c|c|}
\hline \multirow[t]{2}{*}{ Variable } & \multicolumn{2}{|c|}{ Received aggressive treatment } & \multirow[t]{2}{*}{ Wald F P-value } \\
\hline & Adjusted percentages $(95 \% \mathrm{Cl})$ & Odds ratio $(95 \% \mathrm{Cl})$ & \\
\hline Screening history & & & 0.05 \\
\hline Not-screened & $76(74,78)$ & 1.0 & \\
\hline Screened & $70(64,76)$ & $1.5(1.1-2.3)$ & \\
\hline SEER registry & & & $<0.01$ \\
\hline Los Angeles & $71(67,75)$ & 1.0 & \\
\hline Atlanta & $89(85,93)$ & $4.8(2.7-8.5)$ & \\
\hline Connecticut & $77(73,81)$ & $1.5(1.1-2.2)$ & \\
\hline New Mexico & $72(66,78)$ & $\mathrm{I} . \mathrm{I}(0.7-\mathrm{I} .7)$ & \\
\hline Seattle & $73(67,79)$ & $1.2(0.8-1.8)$ & \\
\hline Utah & $77(73,81)$ & $1.5(1.0-2.3)$ & \\
\hline Ethnicity & & & $<0.01$ \\
\hline Non-Hispanic white & $76(74,78)$ & 1.0 & \\
\hline Non-Hispanic black & $69(63,75)$ & $0.6(0.4-0.9)$ & \\
\hline Hispanic & $79(75,83)$ & $1.2(0.8-1.9)$ & \\
\hline Age & & & $<0.01$ \\
\hline$<49$ & $95(92,100)$ & 1.0 & \\
\hline $50-64$ & $89(87,91)$ & $0.4(0.2-1.2)$ & \\
\hline $65-74$ & $79(77,81)$ & $0.2(0.1-0.5)$ & \\
\hline $75+$ & $41(35,47)$ & $0.03(0.01-0.08)$ & \\
\hline Current marital status & & & $<0.01$ \\
\hline Married & $77(75,79)$ & 1.0 & \\
\hline Unmarried & $71(67,75)$ & $0.6(0.5-0.8)$ & \\
\hline Education & & & 0.95 \\
\hline$<$ High school degree & $76(72,80)$ & 1.0 & \\
\hline High school/college & $76(74,78)$ & $1.0(0.7-1.3)$ & \\
\hline College degree & $76(72,80)$ & $0.9(0.7-1.4)$ & \\
\hline Insurance & & & 0.25 \\
\hline Private & $76(74,78)$ & 1.0 & \\
\hline Medicare/Public & $74(68,80)$ & $0.9(0.6-1.4)$ & \\
\hline Unknown & $81(75,87)$ & $1.6(0.9-2.8)$ & \\
\hline Income (annual) & & & 0.98 \\
\hline$<\$ 20,000$ & $76(72,80)$ & 1.0 & \\
\hline$\$ 20-40,000$ & $76(72,80)$ & $1.0(0.7-1.4)$ & \\
\hline$\$ 40,000+$ & $76(72,80)$ & $1.0(0.7-1.5)$ & \\
\hline Comorbid conditions & & & 0.01 \\
\hline None & $78(74,82)$ & 1.0 & \\
\hline 1 & $77(73,81)$ & $0.9(0.7-1.2)$ & \\
\hline 2 & $77(73,81)$ & $0.9(0.6-1.3)$ & \\
\hline $3+$ & $68(62,74)$ & $0.5(0.3-0.7)$ & \\
\hline Health status & & & $<0.01$ \\
\hline Excellent & $80(76,84)$ & 1.0 & \\
\hline Good & $77(75,79)$ & $0.8(0.5-1.2)$ & \\
\hline Fair or poor & $67(61,73)$ & $0.4(0.3-0.7)$ & \\
\hline PSA (ng/ml) & & & $<0.01$ \\
\hline$<4$ & $69(63,75)$ & 1.0 & \\
\hline$\geq 4$ & $77(75,79)$ & $1.7(1.1-2.6)$ & \\
\hline Unknown & $68(60,76)$ & $0.9(0.5-1.9)$ & \\
\hline Gleason score & & & $<0.01$ \\
\hline $2-4$ & $68(62,74)$ & 1.0 & \\
\hline $5-7$ & $78(76,80)$ & $2.0(1.4-2.8)$ & \\
\hline $8-10$ & $71(65,77)$ & $1.2(0.7-2.0)$ & \\
\hline Unknown & $80(74,86)$ & $2.3(1.3-4.2)$ & \\
\hline
\end{tabular}

aAggressive treatment was defined as radical prostatectomy or radiation therapy.

Legend: SEER = Surveillance, Epidemiology, and End Results; PSA = prostate-specific antigen 
disparities in cancer stage at diagnosis [22-24]. However, African Americans also have been reported to demonstrate more skeptical attitudes towards screening [25] and the stage disparity could be due to racial differences in tumor aggressiveness [26].

Men with screening-detected clinically localized cancers were more likely to undergo aggressive treatment with radical prostatectomy or radiation therapy than men with clinically diagnosed cancers. The odds ratio for receiving aggressive treatment was statistically significant at 1.5 , but the adjusted absolute difference between screeningdetected and clinically diagnosed cases was only 6 percentage points. This modest association between screening status and treatment selection suggests that clinical practice may be only partly consistent with the American College of Physicians' view that "aggressive treatment is necessary to realize any benefit from the discovery of a tumor [27]." Our findings may reflect the scientific uncertainty about whether and how to treat screening-detected prostate cancers [28].

Our study has some potential limitations. We classified men presenting with symptoms of advanced cancer as being clinically diagnosed. We do not know that these symptoms actually prompted diagnostic PSA testing. However, the tumor registry medical record abstractors are trained to identify the events leading to a cancer diagnosis; they would attempt to record only symptoms consistent with cancer. Classifying PSA as a screening test is also difficult given the high prevalence of lower urinary tract symptoms in older men [15]. Few members of our study cohort were truly asymptomatic because nearly twothirds reported lower urinary tract symptoms. However, our classifications for clinical diagnosis and screening detection were internally valid because men diagnosed with symptoms of advanced cancer were significantly more likely to present with advanced stage and more aggressive cancers than the combined group of men who were either asymptomatic or had only lower urinary tract symptoms. Additionally, when we compared demographic and socioeconomic characteristics across groups, we generally found that the men with lower urinary tract symptoms alone most closely resembled the asymptomatic men.

Selection bias may have occurred because $44 \%$ of the sampled patients did not complete the 6-month survey. Responders were younger than non-responders, more likely to be non-Hispanic white, had higher socioeconomic status, had earlier stage disease, and were more likely to receive radical prostatectomy. Results may be less generalizable to older men, those with lower socioeconomic status, or members of racial/ethnic groups other than non-Hispanic white. However, these were also the groups who were less likely to have screening-detected cancers. We do not believe that including these nonresponders would have altered our findings on the differences between screening-detected and clinically diagnosed cancers. However, based on their demographics, socioeconomic status, and advanced disease stage, the non-responders were not likely to have a high proportion of screening-detected cancers and thus we may have overestimated the proportion of screening-detected cancers. Another potential limitation arose from asking subjects to recall their baseline symptoms 6 months after diagnosis. Recall errors could lead us to misclassify screening status. However, Legler and colleagues prospectively studied a subset of PCOS subjects and found high concordance for symptom recall at 6-months after diagnosis compared with reports at the time of diagnosis [29]. Finally, we may have had incomplete symptom data, particularly for questions appearing only in the medical record abstract. The abstracts would report a symptom if it appeared in the medical records; the absence of a symptom could be due to either the patient being asymptomatic or the physician's failure to ask about or record the symptom. We performed a sensitivity analysis by using only subject reported symptoms from the survey, then only symptoms reported on the medical record abstract, and then ultimately using a combination of both sources. The results for all analyses were essentially the same.

\section{Conclusion}

The great majority of prostate cancers diagnosed in our study cohort were detected by screening. Appropriately, younger and healthier men were more likely to be diagnosed by screening. Minority status and lower socioeconomic status appeared to be screening barriers. Screening detected earlier stage and less histologically aggressive prostate cancers. After adjusting for baseline demographic, socioeconomic, clinical, and tumor factors, men with a screening-detected clinically localized cancer were slightly more likely to receive aggressive treatment, either radical prostatectomy or radiation therapy, than men with clinically diagnosed cancers.

\section{Competing interests}

The author(s) declare that they have no competing interests.

\section{Authors' contributions}

RMH and ALP initiated the project. SNS co-ordinated the data collection and was responsible for the data analyses. RMH, SNS, DE and ALP prepared the manuscript. All authors read and approved the final manuscript.

\section{Acknowledgements}

This study was supported in part by the U.S Centers for Disease Control and Prevention, Contract U48/CCU610818-06-4; National Cancer Institute, National Institutes of Health, Department of Health and Human Serv- 
ices, Public Health Services contracts N0IPC67007, N0ICN67009, NoIPC67010, N0IPC67006, N0IPC67005, N0IPC67000; and the New Mexico VA Health Care System, Albuquerque, New Mexico.

We thank the men who participated in the Prostate Cancer Outcomes Study and their physicians. We also thank the study teams at each of the research centers for their contributions.

Presented in part at the $26^{\text {th }}$ Annual Meeting of the Society of General Internal Medicine, Vancouver, Canada, May 2, 2003.

\section{References}

I. Kramer BS, Brown ML, Prorok PC, Potosky AL, Gohagan JK: Prostate cancer screening: what we know and what we need to know. Ann Intern Med 1993, I 19:914-23.

2. American Urological Association: Early detection of prostate cancer and use of transrectal ultrasound. In American Urological Association 1992 Policy Statement Book Baltimore, MD: Williams \& Wilkins; 1992.

3. Mettlin C, Jones G, Averette H, Gusberg SB, Murphy GP: Defining and updating the American Cancer Society guidelines for the cancer-related checkup: prostate and endometrial cancers. CA Cancer J Clin 1993, 43:42-6.

4. Stanford JL, Stephenson RA, Coyle LM, Cerhan J, Correa R, Eley JW, Gilliland F, Hankey B, Kolonel LN, Kosary C, Ross R, Severson R, West D: Prostate Cancer Trends 1973-1995 Bethesda, MD: SEER Program, National Cancer Institute; Report No.: NIH Pub. No. 99-4543; 1999.

5. Ries LAG, Eisner MP, Kosary CL, Hankey BF, Miller BA, Clegg L, Mariotto A, Feuer EJ, Edwards BK, eds: SEER Cancer Statistics Review, 1975-200I National Cancer Institute. Bethesda, MD; 2004.

6. Mettlin C: Changes in patterns of prostate cancer care in the United States: results of American College of Surgeons Commission on Cancer studies, 1974-1993. Prostate 1997, 32:221-6.

7. Lu-Yao GL, Friedman M, Yao SL: Use of radical prostatectomy among Medicare beneficiaries before and after the introduction of prostate specific antigen testing. J Urol 1997, 157:2219-22.

8. Mettlin CJ, Murphy GP, Babaian RJ, Chesley A, Kane RA, Littrup PJ, Mostofi FK, Ray PS, Somers WJ, Toi A: Observations on the early detection of prostate cancer from the American Cancer Society National Prostate Cancer Detection Project. Cancer 1997, 80: |8|4-7.

9. Yan Y, Carvalhal GF, Catalona WJ, Young JD: Primary treatment choices for men with clinically localized prostate carcinoma detected by screening. Cancer 2000, 88: I I22-30.

10. Rietbergen JB, Hoedemaeker RF, Kruger AE, Kirkels WJ, Schroder $\mathrm{FH}$ : The changing pattern of prostate cancer at the time of diagnosis: characteristics of screen detected prostate cancer in a population based screening study. J Urol 1999, 16 I: I 192-8.

II. Potosky AL, Harlan LC, Stanford JL, Gilliland FD, Hamilton AS, Albertsen PC, Eley JW, Liff JM, Deapen D, Stephenson RA, Legler J, Ferrans CE, Talcott JA, Litwin MS: Prostate cancer practice patterns and quality of life: the Prostate Cancer Outcomes Study. I Natl Cancer Inst 1999, 9 I: 1719-24.

12. Charlson ME, Pompei P, Ales KL, MacKenzie CR: A new method of classifying prognostic comorbidity in longitudinal studies: development and validation. / Chronic Dis 1987, 40:373-83.

13. Prostate: American Joint Committee on Cancer: AJCC Cancer Staging Manual 5th edition. Philadelphia, Pa: Lippincott-Raven; 1997:219-24.

14. Hennekens $\mathrm{CH}$, Buring JE: Epidemiology in Medicine Boston: Little, Brown; 1987.

15. Chapple CR: Lower urinary tract symptoms suggestive of benign prostatic obstruction - Triumph: design and implementation. Eur Urol 200I, 39(Suppl):3I-6.

16. Harlan L, Brawley O, Pommerenke F, Wali P, Kramer B: Geographic, age, and racial variation in the treatment of local/ regional carcinoma of the prostate. J Clin Oncol 1995, I 3:93-100.

17. Desch CE, Penberthy L, Newschaffer CJ, Hillner BE, Whittemore M, McClish D, Smith TJ, Retchin SM: Factors that determine the treatment for local and regional prostate cancer. Med Care 1996, 34:152-62.
18. Graubard BI, Korn EL: Predictive margins with survey data. Biometrics 1999, 55:652-9.

19. Nelson DE, Bland S, Powell-Griner E, Klein R, Wells HE, Hogelin G, Marks JS: State trends in health risk factors and receipt of clinical preventive services among US adults during the 1990s. JAMA 2002, 287(20):2659-67.

20. Sirovich BE, Schwartz LM, Woloshin S: Screening men for prostate and colorectal cancer in the United States: does practice reflect the evidence? JAMA 2003, 289(I I):|4|4-20.

21. Hoffman RM, Gilliland FD, Eley JW, Harlan LC, Stephenson RA, Stanford JL, Albertson PC, Hamilton AS, Hunt WC, Potosky AL: Racial and ethnic differences in advanced-stage prostate cancer: the Prostate Cancer Outcomes Study. J Natl Cancer Inst 200I, 93:388-95.

22. Baquet CR, Horm JW, Gibbs T, Greenwald P: Socioeconomic factors and cancer incidence among blacks and whites. J Natl Cancer Inst 1991, 83:55|-7.

23. Liff JM, Chow W-H, Greenberg RS: Rural-urban differences in stage at diagnosis. Possible relationship to cancer screening. Cancer 1991, 67:1454-9.

24. Pamies RJ, Woodard LJ: Cancer in socioeconomically disadvantaged populations. Primary Care 1992, 19:443-50.

25. Robinson SB, Ashley M, Haynes MA: Attitudes of African Americans regarding screening for prostate cancer. J Natl Med Assoc 1996, 88:24I-6.

26. Morton RA Jr: Racial differences in adenocarcinoma of the prostate in North American men. Urology 1994, 44:637-45.

27. American College of Physicians: Screening for prostate cancer. Ann Intern Med 1997, I 26:480-4.

28. Harris R, Lohr KN: Screening for prostate cancer: an update of the evidence for the U.S. Preventive Services Task Force. Ann Intern Med 2002, 137:9|7-29.

29. Legler J, Potosky AL, Gilliland FD, Eley JW, Stanford JL: Validation study of retrospective recall of disease-targeted function: results from the prostate cancer outcomes study. Med Care 2000, 38:847-57.

\section{Pre-publication history}

The pre-publication history for this paper can be accessed here:

http://www.biomedcentral.com/1471-2407/5/27/prepub
Publish with Biomed Central and every scientist can read your work free of charge

"BioMed Central will be the most significant development for disseminating the results of biomedical research in our lifetime. "

Sir Paul Nurse, Cancer Research UK

Your research papers will be:

- available free of charge to the entire biomedical community

- peer reviewed and published immediately upon acceptance

- cited in PubMed and archived on PubMed Central

- yours - you keep the copyright
BioMedcentral 